\title{
INTERFACES LEGAIS ENTRE PLANEJAMENTO URBANO E REDUÇÃO DE RISCOS E DESASTRES
}

Cemaden - Centro Nacional de Monitoramento Rertorella Reani Operações e Modelagem São José dos Campos, SP, Brasil
Operastas de Desastres Naturais, Coordenac̃o Geral de reginareani@gmail.com

Érico Soriano

Pesquisador (Pós-doutorado) na Faculdade de Letras da Universidade do Porto (FLUP), Portugal ericogeo@gmail.com

Luciana R Londe Cemaden - Centro Nacional de Monitoramento e Alertas de Desastres Naturais, Coordenação Geral de Pesquisa e Desenvolvimento, São José dos Campos, SP, Brasil luciana.Ionde@cemaden.gov.br

Lívia Rodrigues Tomás Cemaden - Centro Nacional de Monitoramento e Alertas de Desastres Naturais, Bolsista do Programa de Capacitação Institucional - PCI, São José dos Campos, SP, Brasil liviatomas@gmail.com

Maria Lígia Nakamura Guillen Vianna IPPLAN - Instituto de Pesquisa, Administração e Planejamento, São José dos Campos, SP, Brasil maliarquiteta@gmail.com

Cemaden - Centro Nacional de Monitoramento e Alertas de Desastres Naturais, Coordenação Geral de Pesquisa e Desenvolvimento, São José dos Campos, SP, Brasil leonardo.santos@cemaden.gov.br

\begin{abstract}
RESUMO
Os Planos Diretores Municipais têm papel fundamental na gestão de riscos e desastres. Este artigo apresenta estudo da Política Nacional de Proteção e Defesa Civil - PNPDEC (Lei no12.608/12) e da Política Urbana relacionando redução de riscos de desastres e planejamento urbano, tendo o município de São José dos Campos-SP como estudo de caso. O artigo relaciona o macrozoneamento urbano, definido nos Planos Diretores, com as áreas de risco mapeadas no município. Observou-se que as áreas de risco se encontram tanto na área urbana quanto na área rural, porém especialmente em núcleos informais de habitação, motivo pelo qual as moradias não seguem padrões mínimos de construção e urbanismo, o que aumenta o risco de deslizamentos e inundações. Embora haja avanço nos Planos Diretores e na política de redução de riscos de desastres em São José dos Campos, observa-se que a questão de desastres está também relacionada ao processo de urbanização acelerado, falta de fiscalização pelo poder público, déficit habitacional e, carência de políticas sociais que atendam pessoas com recursos insuficientes para a construção de moradias seguras e/ou fora de áreas de risco.
\end{abstract}

Palavras-chave: Legislação. Plano Diretor. Política urbana. Cidades resilientes.

\section{LEGAL INTERFACES BETWEEN URBAN PLANNING AND DISASTER RISK REDUCTION}

\begin{abstract}
Municipal Master Plans have a fundamental role in disaster risk management. In this article, we carried out a study on the National Policy of Protection and Civil Defense PNPDEC (Law no. 12.608/12) and on Urban Policy relating disaster risk reduction and urban planning, considering the municipality of São José dos Campos-SP as a study site. Relating the urban zoning to the risk areas in the municipality, we observe that they are located both in the urban area and in the rural area, where occupation is legal, but does not follow basic building standards, which increases the risk of landslides and floods. Although there are advances in the Master Plans and in the policy of disaster risk reduction in São José dos Campos, the issue of disasters is also related to the growth characteristics of the city (clandestine and irregular
\end{abstract}

$\begin{array}{llllll}\text { Caminhos de Geografia } & \text { Uberlândia-MG } & \text { v. 21, n. 76 } & \text { Ago/2020 } & \text { p. 116-133 Página } 116\end{array}$


subdivisions), and lack of public policies addressed to housing support for low income people.

Keywords: Legislation. Master plan. Urban policy. Resilient cities.

\section{INTRODUÇÃO}

Em janeiro de 2011, na Região Serrana do Rio de Janeiro, ocorreu um dos maiores desastres já registrados no Brasil, decorrente de chuvas intensas que deflagraram processos geodinâmicos e hidrológicos em larga escala, provocando 912 mortes e deixando mais de 45.000 pessoas desalojadas e desabrigadas (BRASIL, 2012b). Este evento levou a mudanças no que se refere à gestão de riscos e desastres no Brasil. O país definiu novas políticas e vem alterando a forma de pensar o planejamento urbano das cidades. A partir deste evento foram criadas novas leis e diretrizes urbanísticas que buscam prevenir e minimizar os danos e prejuízos socioeconômicos decorrentes dos desastres.

Nesse sentido, em 10 de abril de 2012 foi instituída a Política Nacional de Proteção e Defesa Civil (PNPDEC) pela Lei Federal no 12.608/2012, que dispõe sobre o Sistema Nacional de Proteção e Defesa Civil - SINPDEC e o Conselho Nacional de Proteção e Defesa Civil - CONPDEC; além de autorizar a criação de sistema de informações e monitoramento de desastres. A referida lei determina: "É dever da União, dos Estados, do Distrito Federal e dos Municípios adotar as medidas necessárias à redução dos riscos de desastre" (Art. $\left.2^{\circ}\right)$. $\mathrm{O}$ artigo terceiro define:

A PNPDEC deve integrar-se às políticas de ordenamento territorial, desenvolvimento urbano, saúde, meio ambiente, mudanças climáticas, gestão de recursos hídricos, geologia, infraestrutura, educação, ciência e tecnologia e às demais políticas setoriais, tendo em vista a promoção do desenvolvimento sustentável (PNPDEC, 2012, p.02).

Assim, a PNPDEC está diretamente ligada à Política Urbana, como forma de pensar e planejar a cidade, para que estas tenham sinergia na redução dos riscos de desastres. A Política Urbana, principalmente por meio do Plano Diretor, passa a definir áreas de risco e coibir a ocupação e loteamento dessas áreas, sendo esta uma parte da iniciativa necessária para prevenir e minimizar os desastres e promover a criação de cidades mais resilientes.

No contexto de desastres, o risco é o potencial de perda de vidas, danos ou destruição de bens que poderiam ocorrer em um sistema, uma sociedade ou uma comunidade em um período específico de tempo, determinado probabilisticamente como uma função das ameaças, exposição, vulnerabilidade e capacidade (UNISDR, 2017).

No Brasil o aumento dos desastres está intimamente conectado ao crescente processo de subdesenvolvimento e desigualdade social, que leva à ocupação de áreas suscetíveis a desastres. Nas periferias se convivem com situações de pauperização, péssimas condições sociais e exposição cumulativa a diversos tipos de risco (ALVES e TORRES, 2006).

Santos (2012) argumenta que, no Brasil, os desastres estão fortemente associados à ação humana, especialmente com relação ao modo de atuação do poder público para lidar com as relações entre a expansão urbana e as características naturais dos terrenos ocupados. Robaina et al. (2010) afirmam que

a expansão urbana ocorrida nas últimas décadas, associada com a incapacidade do Estado em atender a demanda de moradias, levou a população, principalmente a de baixa renda, a ocupar áreas sujeitas a processos dedinâmica superficial desencadeadores de risco, como planícies de inundação e encostas de morros (ROBAINA et al, 2010, p.159)

Acselrad (2006) enfatiza que as condições de vulnerabilidade e de exposição aos riscos não decorrem de fenômenos naturais, mas sim de processos de vulnerabilização, ou seja, de processos sociais, históricos e territorialmente circunscritos, cujas práticas econômicas e político-institucionais contribuem para tornar determinados grupos sociais vulneráveis, para vulnerabilizá-los. Os mecanismos de produção dessa desigualdade ambiental caracterizam-se pela "exposição desproporcional dos socialmente mais desprovidos aos riscos das redes técnico-produtivas da 
riqueza ou sua despossessão ambiental pela concentração dos benefícios do desenvolvimento em poucas mãos" (ACSELRAD, 2010, p.109).

Quando ocorre a ocupação sem o devido planejamento do espaço, os impactos são significativos (TUCCI, 2005). No planejamento e no controle do uso do espaço, do parcelamento e da ocupação do solo urbano, os municípios têm competência para promover um ordenamento territorial adequado quando for necessário e legislar sobre assuntos de interesse local (MARTINS, 2003).

O espaço está sendo continuamente produzido, o mundo tem se tornado urbano e as cidades sintetizam a problemática do mundo contemporâneo. O espaço urbano é submetido à lógica do valor, esta que é capaz de mover a produção e reprodução capitalista da sociedade (SEABRA, 2012). Na cidade, a transformação da primeira natureza em segunda natureza é evidente. Como aponta Lefebvre (1974), o espaço natural é reduzido e transformado em um produto social. Carlos (2007) ao fazer uma leitura geográfica sobre a cidade mostra que a cidade é uma produção humana, formada por ações passadas e presentes, e está relacionada à vida humana. A autora op. cit. ainda afirma que há uma indissociabilidade entre espaço e sociedade, uma vez que as relações sociais se materializam em território real e concreto, e desta forma, ao produzir a sua vida, a sociedade produz e reproduz um espaço através da prática socioespacial. "[...] Tal fato torna o processo de produção do espaço indissociável do processo de reprodução da sociedade - neste contexto, a reprodução continuada da cidade ocorre fundamentando-se na reprodução ininterrupta da vida" (CARLOS, 2007, p. 21).

\begin{abstract}
O espaço urbano representa, antes de mais nada, um uso, ou ainda, um valor de uso, e desta maneira, a vida se transforma, com a transformação dos lugares de realização de sua concretização, que a norma se impõe e que o Estado domina a sociedade, organizando, posto que normatiza os usos através dos interditos e das leis (CARLOS, 2007, p.30).
\end{abstract}

Neste sentido, o urbano, como aponta Carlos (2008), reproduz-se, de um lado, de forma "espontânea", no livre jogo do mercado, e de outro, "planejada", na medida em que o Estado passa a intervir cada vez mais na produção da infraestrutura ou na criação de leis de zoneamento urbano. No entanto, as ações do Estado capitalista favorecem a classe dominante e o capital, e tornam ainda mais profundas as desigualdades sociais e a luta de classes. $O$ Estado tem papel fundamental na produção do espaço, posto que "[...] interfere diretamente no processo de produção do espaço, seja como produtor direto, seja como criador de infraestrutura, de mecanismos de 'planificação', ou ainda através de leis e decretos" (CARLOS, 2008, p. 201).

As múltiplas relações entre espaço, sociedade e Estado manifestam-se também na temática dos Desastres. Ferreira, Albino e Freitas (2011) destacam como as principais causas dos desastres no Brasil: ocupação incorreta do solo; ineficácia política nos âmbitos municipal, estadual e/ou federal; fraca organização dos serviços de proteção e defesa civil e a dificuldade de envolvimento das comunidades em atividades de prevenção. Os escorregamentos e as inundações, no Brasil, estão associados, principalmente, à utilização do solo para atividades antrópicas, sem o cuidado de harmonizar o desenvolvimento econômico e social e as questões ambientais (ROBAINA, 2008).

Para lidar com o aparecimento e/ou o crescimento de áreas e de situações de risco, é essencial planejar o uso e a ocupação do território, considerando as características e as limitações naturais do terreno (VEDOVELLO e MACEDO, 2007), além da adoção de medidas complementares em apoio às intervenções planejadas, que também apresentam limitações e dificuldades. Nesse sentido, as políticas urbanísticas previstas no Estatuto da Cidade, alteradas pela Política Nacional de Proteção e Defesa Civil, definem medidas que inibem a ocupação de áreas suscetíveis a deslizamentos e inundações e reforçam a necessidade da atuação dos estados e municípios na redução de desastres na esfera local.

Conforme documento produzido pelo Ministério das Cidades:

Os deslizamentos de encostas, as inundações e enxurradas representam os fenômenos naturais que produzem o maior número de mortes e danos entre a população das nossas cidades. Como o município é o ente federado a quem foi atribuído, pela Constituição Federal, a competência pela política urbana, ele é o principal responsável por instituir uma política de desenvolvimento urbano que contemple o gerenciamento dos riscos (CARVALHO e GALVÃO, 2013, p. 2). 
Considerando que há muitos estudos sobre fenômenos naturais em áreas urbanas, mas poucos sobre as diversas interações entre as características de uso e ocupação do solo, as políticas públicas e os desastres, este artigo tem como objetivo analisar a Política Nacional de Proteção e Defesa Civil (Lei no 12.608/2012) e a Política Urbana como instrumentos de planejamento urbano para redução de riscos de desastres na esfera municipal. Para tanto, foi considerado como estudo de caso o município de São José dos Campos (SP), por ser um município que teve intervenção do Estado, possuindo quatro Planos Diretores, e com histórico de desastre de deslizamento e inundação. O estudo teve como base a Política Nacional de Proteção e Defesa Civil (Lei nº 12.608/2012), Política Urbana (Artigos 182 e 183 da Constituição Federal 1988), Estatuto da Cidade (Lei n 10.257/2001) e Lei do Parcelamento do Solo Urbano (Lei no 6.766/79), bem como análise da evolução dos Planos Diretores $(1961 ; 1971 ; 1995 ; 2006)$ de São José dos Campos, com foco na expansão urbana e macrozoneamento, e estudo do Plano Municipal de Redução de Riscos para inundações e deslizamentos do município (PMSJC, 2016).

\section{FUNDAMENTAÇÃO LEGAL}

\section{A política nacional de proteção e defesa civil e a política urbana}

Em 10 de abril de 2012 foi instituída a Política Nacional de Proteção e Defesa Civil (PNPDEC), pela Lei Federal no 12.608/2012, na tentativa de minimizar os impactos dos desastres no Brasil. Para tanto, altera leis importantes na escala municipal, como o Estatuto da Cidade e a Lei de Parcelamento do Solo (Figura 1). A Lei Federal no 12.608/2012 (PNPDEC), traz uma série de normas e diretrizes para as ações de proteção e defesa civil com o objetivo de reduzir os riscos de desastres no país, que incidem diretamente sobre as atividades de planejamento urbano. Entre seus objetivos é possível destacar: a incorporação da redução do risco de desastres e ações de proteção e defesa civil entre os elementos da gestão territorial; a promoção do desenvolvimento de cidades resilientes e de processos sustentáveis de urbanização; o controle da ocupação de áreas ambientalmente vulneráveis e de risco e a promoção da realocação da população residente nessas áreas (Art.5).

Figura 1 - Interfaces da Política Nacional de Proteção e Defesa Civil Lei (Federal no 12.608/2012), Política Urbana e Parcelamento do Solo.

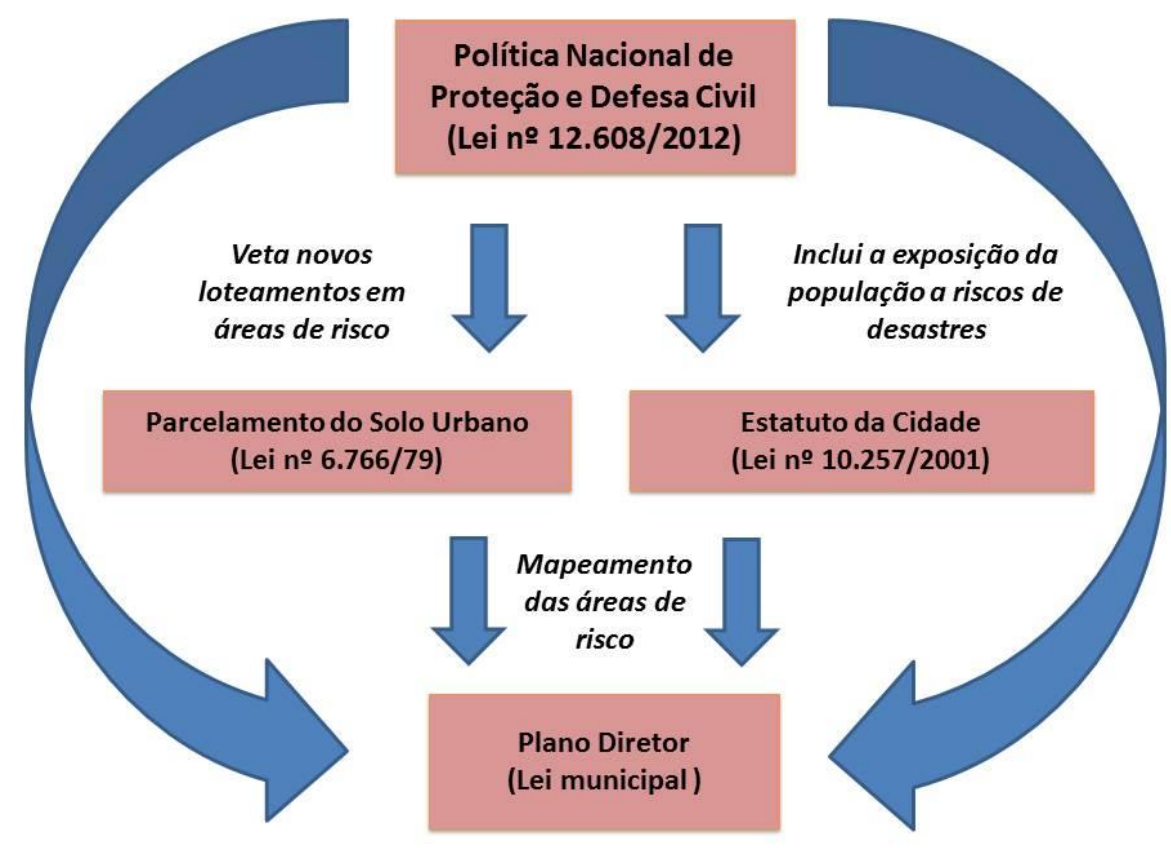

Fonte - Elaborado pelos autores.

$\begin{array}{lllll}\text { Caminhos de Geografia } & \text { Uberlândia-MG } & \text { v. 21, n. 76 } & \text { Ago/2020 } & \text { p. 116-133 Página } 119\end{array}$


Um dos mecanismos da Política Nacional de Proteção e Defesa Civil (PNPDEC - Lei Federal no 12.608/2012) para redução de risco de desastres, de competência da União, é instituir e manter o Cadastro Nacional de Municípios com áreas suscetíveis a deslizamentos de grande impacto, inundações bruscas ou processos geológicos ou hidrológicos correlatos. A legislação prevê também que compete à União instituir e manter sistema de informações e monitoramento de desastres, e produzir alertas sobre a possibilidade de ocorrência de desastres (Art.6).

Ao Município compete, entre outros: incorporar as ações de proteção e defesa civil no planejamento municipal; identificar e mapear as áreas de risco de desastres; promover a fiscalização das áreas de risco e vedar novas ocupações nessas áreas (Art.8). De acordo com levantamento realizado pela Prefeitura de São José dos Campos, o município possui atualmente 54 áreas de risco de deslizamentos e/ou inundação. Destas, foram mapeadas e avaliadas 17 áreas de risco de deslizamento, somando mais de 6.000 pessoas expostas ao risco (PMSJC, 2016).

Desta forma, São José dos Campos está sujeito a sofrer alterações em sua legislação, uma vez que a Lei Federal ํo 12.608/12 impõe novas diretrizes ao planejamento urbano e uso e ocupação do solo para municípios com áreas de risco, tendo como objetivo prevenir e minimizar os impactos causados por desastres no Brasil.

A Legislação prevê que os municípios deverão elaborar mapeamento de áreas suscetíveis a desastres deflagrados por fatores geológicos/hidrológicos; elaborar plano de obras e serviços para redução de risco de desastres; criar mecanismos de controle e fiscalização para evitar a edificação em áreas suscetíveis à ocorrência destes desastres; elaborar carta geotécnica de aptidão à urbanização, estabelecer diretrizes urbanísticas voltadas para a segurança dos novos parcelamentos do solo (Art.22). A lei ainda veda a concessão de licença ou alvará de construção em áreas de risco indicadas como não edificáveis no plano diretor ou legislação dele derivada (Art.23).

A Lei Federal no 12.608/12 traz mudanças à Política Urbana, em especial ao Estatuto da Cidade (Lei Federal no 10.257/01), que passa a ter novas diretrizes incorporando a questão das áreas de risco e população exposta ao risco de desastres. O Art. 25 torna o Plano Diretor obrigatório para os municípios incluídos no Cadastro Nacional de municípios com áreas suscetíveis à ocorrência de desastres.

O Art. 26 da Lei no 12.608/12 faz grandes alterações aos Artigos 42-A e 42-B do Estatuto da Cidade, incluindo ações específicas no Plano Diretor que tratam do planejamento urbano e da prevenção de desastres. Assim, uma série de ações deverá fazer parte do Plano Diretor, como: identificação e mapeamento de risco com base em cartas geotécnicas; mapeamento de áreas suscetíveis à ocorrência de desastres; ações de intervenção e relocação de populações de áreas de risco; medidas de drenagem urbana para prevenção e mitigação de impactos de desastres; identificação e diretrizes para a preservação e ocupação das áreas verdes municipais, com vistas à redução da impermeabilização das cidades; mapeamento de áreas de risco considerando as cartas geotécnicas. Para a ampliação do perímetro urbano, o município deve prever a delimitação dos trechos com restrições à urbanização e dos trechos sujeitos a controle especial em função de ameaça de desastres.

A Lei $n^{\circ}$ 12.608/12, em seu Art. 27, altera ainda a Lei Federal o 6.766/79 que dispõe sobre parcelamento do solo urbano, passando a determinar que os municípios inseridos no Cadastro Nacional de Municípios com áreas suscetíveis à ocorrência de desastres só terão projeto de loteamento aprovado com o atendimento dos requisitos constantes da carta geotécnica de aptidão à urbanização. A Lei ainda veda a aprovação de projetos de loteamento e desmembramento em áreas de risco definidas como não edificáveis no Plano Diretor ou em legislação dele derivada.

É possível relacionar a Lei Federal no 6.766/79 (Lei de Parcelamento do Solo Urbano) com a prevenção de riscos geo-hidrológicos e ao planejamento urbano, principalmente no conteúdo do 
Art. $3^{\circ}$, que determina que só será admitido o parcelamento do solo para fins urbanos em zonas urbanas, de expansão urbana ou de urbanização específica, assim definidas pelo Plano Diretor ou aprovadas por lei municipal. O mesmo artigo determina ainda que não será permitido 0 parcelamento do solo nas seguintes condições:

- $\quad$ em terrenos alagadiços e sujeitos a inundações, antes de tomadas as providências para assegurar o escoamento das águas,

- $\quad$ em terrenos com declividade igual ou superior a 30\% (trinta por cento),

- $\quad$ em terrenos onde as condições geológicas não são favoráveis à edificação.

Recorrentemente, a Lei nº 12.608/2012 manifesta a necessidade da revisão do Plano Diretor com a incorporação das informações de áreas de risco de desastres. Observa-se deste modo a relação entre a Política Nacional de Proteção e Defesa Civil e as medidas que incidem sobre o planejamento urbano para redução do risco de desastres, sendo que o Plano Diretor se mostra como um dos principais instrumentos da política urbana na prevenção de riscos.

Para Almeida (2015, p.2), "a mobilização política mostrou-se refém da ocorrência de desastres para se organizar, evidenciando uma precária capacidade de prevenção e mitigação desses eventos". As estratégias iniciais de gerenciamento de risco de desastres no Brasil tiveram foco nas ações de resposta e recuperação (períodos do impacto e pós-impacto), sendo repensadas a partir da Lei no 12.608/12, que direciona os esforços de gerenciamento de risco de desastres para a prevenção (ALMEIDA, 2015). Na atual PNPDEC, pela primeira vez a política de proteção e defesa civil é pensada de forma integrada com políticas em outras áreas, trazendo modificações não só à Defesa Civil como na Lei do Estatuto da Cidade, na Lei de Parcelamento do Solo Urbano e na Lei de Diretrizes e Bases da Educação Nacional (ALMEIDA, 2015).

\section{Instrumentos de planejamento em são josé dos campos}

O município de São José dos Campos possui população estimada de 721.944 habitantes (IBGE, 2019), sendo o $7^{\circ}$ município do estado de São Paulo em tamanho populacional; faz parte da Região Metropolitana do Vale do Paraíba e Litoral Norte (Lei Estadual no 1.166/12), que compreende 39 municípios e população de 2.489.629 habitantes (SEADE, 2020). O município apresenta o 8 maior PIB do Estado de São Paulo (IBGE, 2010).

O município teve seu desenvolvimento inicial na agricultura do café, mas com o declínio da produção passou por uma fase sanatorial, quando passou a receber doentes com tuberculose, e houve necessidade de rever o planejamento e as políticas públicas, recebendo verbas do governo municipal e estadual para investimentos na área de saúde e em melhorias urbanas. 0 desenvolvimento do município e a proximidade com a capital paulista favoreceram o processo de industrialização. Mais uma vez o Estado teve grande intervenção no município com a implantação do Centro Técnico da Aeronáutica (1948), Rodovia Presidente Dutra/BR-116 (1951), Embraer (1969), Instituto Nacional de Pesquisas Espaciais - INPE (década de 1960) e a Refinaria da Petrobrás (década 1980). As ações do Estado levaram a certo planejamento do município, porém aliado há um processo de rápida industrialização e crescimento urbano (REANI, 2012).

Tais fatores levaram o município a ser escolhido como estudo de caso, uma vez que houve ações de planejamento urbano, com o primeiro Plano Diretor em 1961 e intervenções do Estado, possui grande desenvolvimento econômico e industrial, porém enfrenta problemas com a ocupação de áreas de risco suscetíveis a deslizamentos e inundações, com histórico de ocorrências de desastres com óbitos e grandes perdas sociais e econômicas no município. Acredita-se que a Política Nacional de Proteção e Defesa Civil (Lei Federal no 12.608/2012), pode ser utilizada para melhor planejamento do município e redução de risco de desastres, uma vez que o município está 
elaborando o Plano Municipal de Redução de Risco (PMSJC, 2016) e encontra-se em elaboração do novo Plano Diretor.

São José dos Campos teve quatro Planos Diretores $(1961,1971,1995,2006)$. O primeiro Plano Diretor (1961) fez um estudo relevante sobre o município, considerando seus aspectos sociais, econômicos e ambientais, porém não foi aprovado na forma de lei, sendo parcialmente implantado por meio de decretos. Já o Plano Diretor de 1971 foi promulgado pela Lei nº 1.623/71 e deixou clara a vocação industrial assumida pelo município. A ação do Estado, caracterizada pelo regime militar, foi marcante neste período.

O Plano Diretor foi acompanhado da Lei de Zoneamento Urbano (Lei oㅡ 1.606/71) e o uso do solo industrial foi privilegiado no município: $65,1 \%$ do espaço urbano foram definidos como zona industrial ou zona predominantemente industrial. $O$ aspecto ambiental não recebeu atenção nesta versão do Plano Diretor, sendo que a expansão urbana do município foi pensada em três fases e a última delas previa a ocupação da várzea do Rio Paraíba, desconsiderando questões ambientais (REANI, 2012). O Plano diretor de 1971 foi incipiente quanto às questões de drenagem urbana e manejo dos recursos hídricos.

O Plano Diretor de 1995, bem diferente do anterior, foi elaborado em uma fase de abertura política do país e levou em consideração os aspectos sociais e ambientais do município, além dos econômicos. Sendo assim, ele foi elaborado com base em estudos preliminares, em especial, na Carta das Unidades Territoriais de Características Físicas e Antrópicas Homogêneas (desenvolvida pelo INPE pelo Instituto de Pesquisas Tecnológicas - IPT), que identificou as potencialidades e limitações para uso e ocupação solo (PMSJC, 1995a).

Em relação aos recursos hídricos esta Carta identificou áreas de inundações, planícies aluviais e de impermeabilização. Por exemplo, identificou a Unidade 1 (Área de Preservação Ambiental APA IV), atualmente conhecida como APA do Banhado, como área planícies aluviais (várzea) e terraços fluviais do Rio Paraíba (Figura 2). A Carta também apontou que terrenos nessa região são altamente problemáticos para ocupação urbana, devido às extremas dificuldades de implantação de obras de saneamento e drenagem, de realização de escavações e de construção de fundações e também por estarem sujeitos ao acúmulo de águas do escoamento superficial provenientes da impermeabilização urbana a montante (REANI, 2012).

O estudo preliminar do Plano Diretor de 1995 destacou ainda na caracterização da Unidade 4, atual APA III, a presença de cabeceiras de drenagem da maior parte dos córregos que cortam a área urbana do município e a necessidade de sua preservação:

[...] O aumento do grau de impermeabilização em decorrência do adensamento urbano, geraria maiores contribuições ao sistema hídrico, acarretando também significativo incremento às velocidades dos fluxos, fato que implicaria em sérios problemas de escoamento de águas principalmente nas travessias mais antigas, sob o sistema viário, que no geral não foram dimensionadas para esta situação (PMSJC, 1995a, p.74).

A Unidade 6, que compreende a zona rural, apresentou alto potencial de risco geológico e forte erodibilidade com ocorrência de deslizamento, como descrito no estudo desenvolvido pela Prefeitura, que considerou a região altamente problemática para qualquer instalação urbana e de estruturas viárias (PMSJC, 1995a). Desta forma, o estudo preliminar do PD-1995 já mostrava preocupação em relação à ocupação urbana, à drenagem urbana, e aos riscos de inundações e deslizamentos, que, de acordo com o texto deste documento, a preservação das Unidades 1, 4 e 6 (atuais APA II, III e IV) do território eram imprescindíveis para garantir a qualidade das águas e prevenir problemas de inundações na malha urbana consolidada a jusante e na área de expansão urbana (Figura 2). O estudo também apontava dados e mapa de Áreas de Risco sujeitas a 
inundações e deslizamentos: "[...] o crescimento da malha urbana tem incorporado áreas tecnicamente inadequadas ao assentamento urbano, acarretando problemas de degradação do meio físico e expondo a população à riscos" (PMSJC, 1995a, p.114). Foram apontados vários exemplos deste problema:

- Implantação de loteamentos em locais não apropriados sob o ponto de vista geotécnico;

- Aterro e ocupação de várzeas ao longo dos rios e córregos, expondo a população a inundações. Problemas com estas características são observados no Jardim Pararangaba, Vila Cristina, Vila Guarani;

- $\quad$ Ocupação de morros e encostas, expondo essas populações a possíveis escorregamentos de terra e soterramentos, a exemplo da Vila São Bento, Vila Letônia, Jardim Guimarães;

- Conflitos na ocupação do solo das áreas de preservação permanente (APP) ao longo dos rios e córregos, necessitando de estudos técnicos de macrodrenagem para determinar a cota de inundação dos terrenos ao longo desses recursos hídricos.

Assim, com base no estudo preliminar, o Plano Diretor de 1995 (Lei no 121/95), determinou no Art. 21 que dentre as diretrizes para ocupação urbana o sistema de planejamento físico e territorial deveria ser embasado em alguns instrumentos, destacando-se: “(a) Carta Geotécnica e Hidrológica; (b) Carta de Macrodrenagem; (c) Carta das Unidades Territoriais. O Art. 15 considerou a Unidade 1 imprópria para o desenvolvimento urbano e a implantação de obras viárias e destinou a Unidade 4 como área de proteção das cabeceiras de drenagem. O Art. 17 especificou que devido às características de seu solo e de suas condições hídricas, a APA IV apresenta alta restrição à implantação de atividades urbanas (Figura 1). O Art. 20 apontou que na APA III existem inúmeras cabeceiras de drenagem e alto potencial de riscos geológicos, sendo, portanto, inadequada à ocupação urbana, motivo pelo qual determinou que: [...] "a preservação desta porção do território é imprescindível para garantir a qualidade das águas e prevenir graves problemas de enchentes e inundações na malha urbana consolidada à jusante e na Macrozona de Expansão Urbana I".

No Art.39 do Plano Diretor de 1995, o "Programa de controle e prevenção da erosão urbana" foi definido como um dos programas prioritários da Política Municipal do Meio Ambiente, e era constituído por três itens:(a) a criação de diretriz municipal de controle e prevenção de problemas erosivos que considerassem não só os dispositivos legais específicos, mas também os mecanismos que garantissem sua observância; (b) a elaboração de carta geotécnica com o intuito de determinar a ocupação e uso do solo, de acordo com seu potencial urbano, agrícola, minerário, identificando as áreas de risco e de preservação permanente; e (c) a definição de medidas de recuperação de áreas degradadas e ações no âmbito do uso do solo, drenagem urbana, preservação e recuperação da cobertura vegetal e educação ambiental. O Art.66, que trata da Política Municipal de Habitação, definiu como um dos seus programas prioritários a implantação do plano de gerenciamento e recuperação de áreas de risco.

Observa-se deste modo que o PD-1995 abordou a questão da drenagem urbana, uso do solo e moradias em áreas de risco, considerou os problemas de inundação e deslizamento já existentes no município, planejou ações de proteção das cabeceiras de drenagem, planícies de inundação e solos suscetíveis a deslizamento de modo a evitar problemas futuros, criou programas e ações para gerenciamento de áreas de risco e previu medidas para a redução dos riscos de desastres.

O último Plano Diretor de São José dos Campos de 2006 - ainda vigente e em processo de revisão - foi elaborado a partir do PD-1995. Ao discutir a organização territorial do município, o PD 2006 utilizou, também, a Carta das Unidades Territoriais desenvolvida para o PD-1995, mantendo assim a mesma base técnico-científica e ressaltando os estudos já realizados anteriormente (Figura 2), porém não avançou na caracterização e atualização de informações sobre a organização territorial do município. No entanto, ao final do estudo há uma lista dos principais impasses urbanos existentes no município, que aumentam o risco de desastres socioambientais, destacando-se: 
- Ineficiência de critérios para coibir a ocupação inadequada dos fundos de vales, várzeas e áreas de recarga de aqüíferos;

- Altas taxas de impermeabilização no modelo de ocupação urbana da época, não considerando os limites de sustentabilidade do sistema hídrico superficial e subterrâneo, em especial quanto à permeabilidade do solo;

- Implantação de loteamentos com tamanhos de lotes inadequados em relação à topografia.

Deste modo, o Plano Diretor-2006, instituído pela Lei Complementar oㅜ 306/2006, novamente apontou a necessidade de proteção das APAs I, II e III devido ao alto potencial de risco geológico e à necessidade de prevenção de inundações na malha urbana à jusante (Art.12).

Figura 2 - São José dos Campos (SP): Carta das Unidades Territoriais de Características Físicas e Antrópicas (INPE e IPT), Macrozoneamento do Plano Diretor de 1995 e Macrozoneamento do Plano Diretor de 2006.
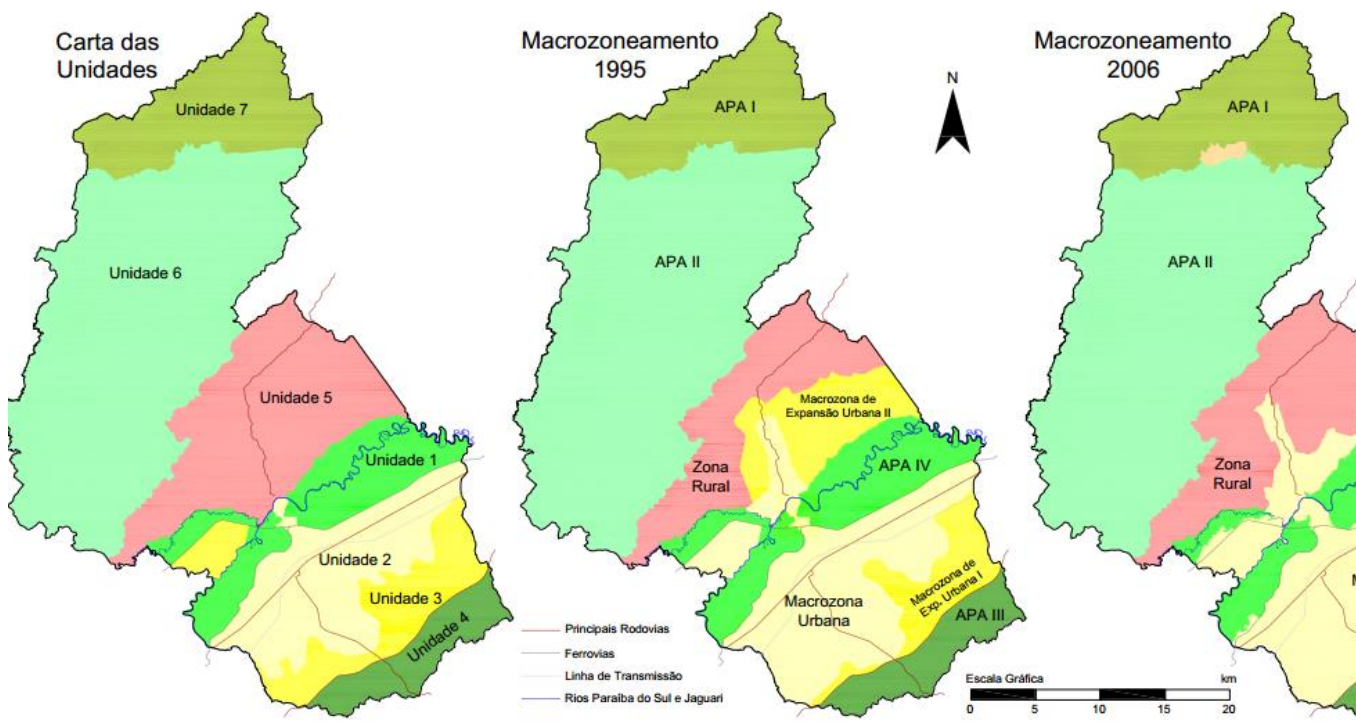

Fonte - Reani (2012).

O PD-2006 definiu a Política de Macrodrenagem Urbana, que consistiu em "criar mecanismos de gestão de infraestrutura urbana relacionados com o escoamento das águas pluviais e dos rios em áreas urbanas da cidade, além da utilização de medidas estruturais e não estruturais para 0 controle das cheias (Art. 64)".O Art. 65 do PD-2006 definiu as diretrizes gerais da política de macrodrenagem urbana, destacando-se: estabelecimento de plano de ocupação das bacias hidrográficas; definição das áreas alagáveis e áreas para implantação das bacias de retenção no Córrego Senhorinha, Ribeirão Vidoca, Ribeirão Cambuí/ Putins, Rio Alambarí, Rio Pararangaba, Rio Comprido, Córrego Nossa Senhora da Ajuda do Bom Retiro e Rio Buquira; elaboração de plano de Manejo e utilização dos recursos hídricos; definição de parâmetros necessários para evitar a impermeabilização do solo na política de parcelamento, uso e ocupação do solo; e promoção de obras de manutenção da infraestrutura.

No entanto, a partir do que foi previsto na lei, apenas as diretrizes referentes ao uso e ocupação do solo foram consolidadas, no sentido da preservação das áreas de várzea. A redução da impermeabilização pretendida com a demarcação de áreas de controle de impermeabilização foi considerada na lei de parcelamento do solo, exigindo um acréscimo do percentual de áreas verdes nos loteamentos localizados nessas áreas. À exceção destes dois fatores, o restante não foi 
executado. O Mapa 06 anexo ao PD-2006 apresentava as bacias de retenção necessárias para conter as cheias a jusante nos referidos córregos, não se tendo informação sobre sua implantação ou não (PMSJC, 2006).

O risco de desastres associados a processos hidrológicos e de movimentos de massa existe há longo tempo no município e foi abordado nos Planos Diretores de 1995 e 2006, destacando a importância da proteção das planícies aluviais (várzeas) e terraços fluviais do Rio Paraíba do Sul e das cabeceiras de drenagem, criação de APAs e restrições ao uso do solo. Os Planos Diretores destacaram ainda a importância de restringir a impermeabilização do solo. No entanto, nem todas as diretrizes previstas em lei foram colocadas em prática. Somando-se o elevado crescimento populacional e o adensamento urbano, há um agravamento dos problemas geo-hidrológicos no risco de desastres no município, causando, entre outros, danos à mobilidade urbana, habitação e saúde, além de prejuízos econômicos.

\section{Risco de desastres no município de são josé dos campos}

Os desastres já foram caracterizados anteriormente por sua relação com processos físicos de grande intensidade e com consequências gravíssimas. Para Valencio (2005), a concretização do desastre ocorre no processo social e histórico de um determinado espaço (geográfico e social) e tempo (cronológico e social), e sua crise se dá quando um fenômeno físico (chuvas, por exemplo) encontra a base material e simbólica construída nesse processo.

Atualmente, a versão mais atual da UNISDR (2017) define desastres como

uma séria interrupção do funcionamento de uma comunidade ou de uma sociedade em qualquer escala devido a eventos perigosos que interagem com condições de exposição, vulnerabilidade e capacidade, levando a uma ou mais das seguintes: perdas e impactos humanos, materiais, econômicos e ambientais (UNISDR, 2017, p.13).

As adaptações e atualizações das definições aproximam-se da definição de Valencio (2005, p.163164): "A concretização do risco, isto é, uma interação deletéria entre um evento natural ou tecnológico e a organização social, que coloca em disrupção as rotinas de um dado lugar e gera elevados custos (temporais, materiais e psicossociais) de reabilitação e reconstrução".

A nova terminologia da UNISDR (2017) também considera o conceito de "build backbetter" (reconstruir melhor), em oposição a definições anteriores que tratavam do retorno a condições semelhantes àquelas anteriores ao impacto.

O município de São José dos Campos apresenta suscetibilidade a desastres relacionados a eventos extremos de precipitação e associados a processos de urbanização e características inadequadas de uso e ocupação do solo, resultando em inundações e movimentos de massa. Mendes et al. (2015) concluíram que tanto uma chuva diária, com valores entre 20 e $50 \mathrm{~mm}$ em um período de 24 horas, quanto um acumulado de precipitação de três dias, com valores superiores a $50 \mathrm{~mm} / 72$ horas, são valores considerados suficientes para desencadearem processos de escorregamento no município.

Nesta linha de estudo, Santos et al. (2015) apresentaram o caso de um episódio de precipitação ocorrido em São José dos Campos, no qual um Complexo Convectivo de Mesoescala gerou precipitação com taxas superiores a $15 \mathrm{~mm}$ em 10 minutos, acumulando $59 \mathrm{~mm}$ em um intervalo de apenas uma hora, ou seja, ultrapassando os valores mínimos de precipitação, com potencial de ocorrência de um desastre, o que gerou a inundação em uma determinada área da cidade.

Com base nas ocorrências registradas no Sistema Integrado de Informações sobre Desastres (S2ID) do Ministério do Desenvolvimento Regional, São José dos Campos registrou, entre os anos

\begin{tabular}{llllll}
\hline Caminhos de Geografia & Uberlândia-MG & v. 21, n. 76 & Ago/2020 & p. 116-133 Página 125
\end{tabular}


de 2002 e 2013, um total de sete casos de inundação, 10 alagamentos, cinco deslizamentos e uma enxurrada (o S2ID não possui eventos registrados a partir de 2013) (BRASIL, 2019). Embora sem registro em fontes oficiais, há notícias recentes divulgadas na mídia de deslizamentos e inundações com pessoas afetadas, no Bairro Freitas, onde um deslizamento levou quatro pessoas a óbito (PORTAL G1, 2016).

De acordo com o Relatório Preliminar do Plano Municipal de Redução de Risco (PMSJC, 2016), São José dos Campos possui atualmente 54 áreas consideradas de risco para deslizamento e/ou inundação, distribuídas em 46 bairros, sendo 35 áreas de deslizamento e 19 áreas de inundação (PMSJC, 2016), conforme mostra a Figura 3.

Figura 3 - São José dos Campos (SP): Localização das áreas de risco de deslizamento e inundação sobre Macrozoneamento, 2006.

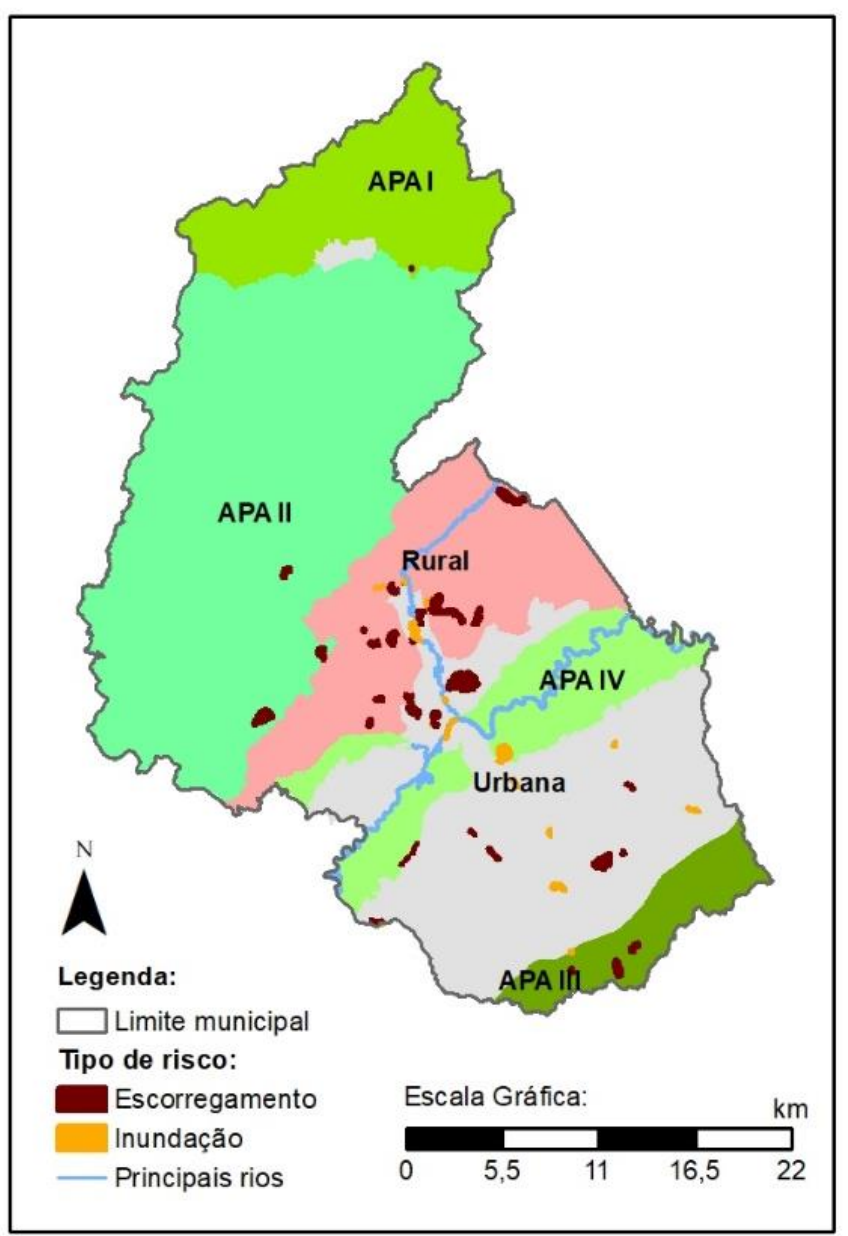

Fonte - Reani (2012); PMSJC (2016).

O Relatório Preliminar do Plano Municipal de Redução de Risco, em fase de finalização, trabalha com 17 áreas de risco de deslizamento, que se dividem em 77 setores com diferentes graus de risco, sendo que 55 destes apresentam risco alto ou muito alto de deslizamento. Nestas 17 áreas existem 1.250 moradias e aproximadamente 6.250 pessoas expostas ao risco (PMSJC, 2016).

O custo estimado no ano de 2016 para a adoção de medidas estruturais como: muro de arrimo, limpeza, drenagem e redução do risco nas 17 áreas consideradas como de Risco Alto e Risco 
Muito Alto de escorregamento no município de São José dos Campos foi de $\mathrm{R} \$ 38.233 .857,44$, apresentando um custo médio de $\mathrm{R} \$ 35.280,59$ por moradia beneficiada com as medidas estruturais (PMSJC, 2016, p. 48). Como consta no Relatório Preliminar, este custo é estimado e pode variar de acordo com o tipo de obra mais conveniente para cada local. Considerando que no total o município possui 54 áreas de riscos, o gasto com medidas estruturais poderá ser três vezes maior que o valor estimado.

A maioria das áreas de risco de São José dos Campos não coincide com as áreas problemáticas à ocupação urbana (APAs), conforme os Planos Diretores de 1995 e 2006 . Observa-se, pelo histórico de ocorrências de deslizamento no município e pela localização das áreas de risco, que a maior parte destas áreas localiza-se na zona urbana, ou em locais de ocupação legal na zona rural (Figura 3). No entanto, o que se observa são moradias precárias (Figura 4), construídas em corte/aterro, em encostas e sem padrões urbanísticos mínimos, ou seja, não respeitam as leis de construção, e também, observa-se a construção de loteamentos clandestinos e irregulares, fora do padrão construtivo previsto em lei e que desrespeitam o lote mínimo, em especial na área rural, estabelecido no Plano Diretor Municipal. A falta de políticas habitacionais aliada a falta de fiscalização do Poder Público e o se fazer cumprir das leis urbanísticas, leva a construção de moradias precárias que favorecem a ocorrência de desastres no município.

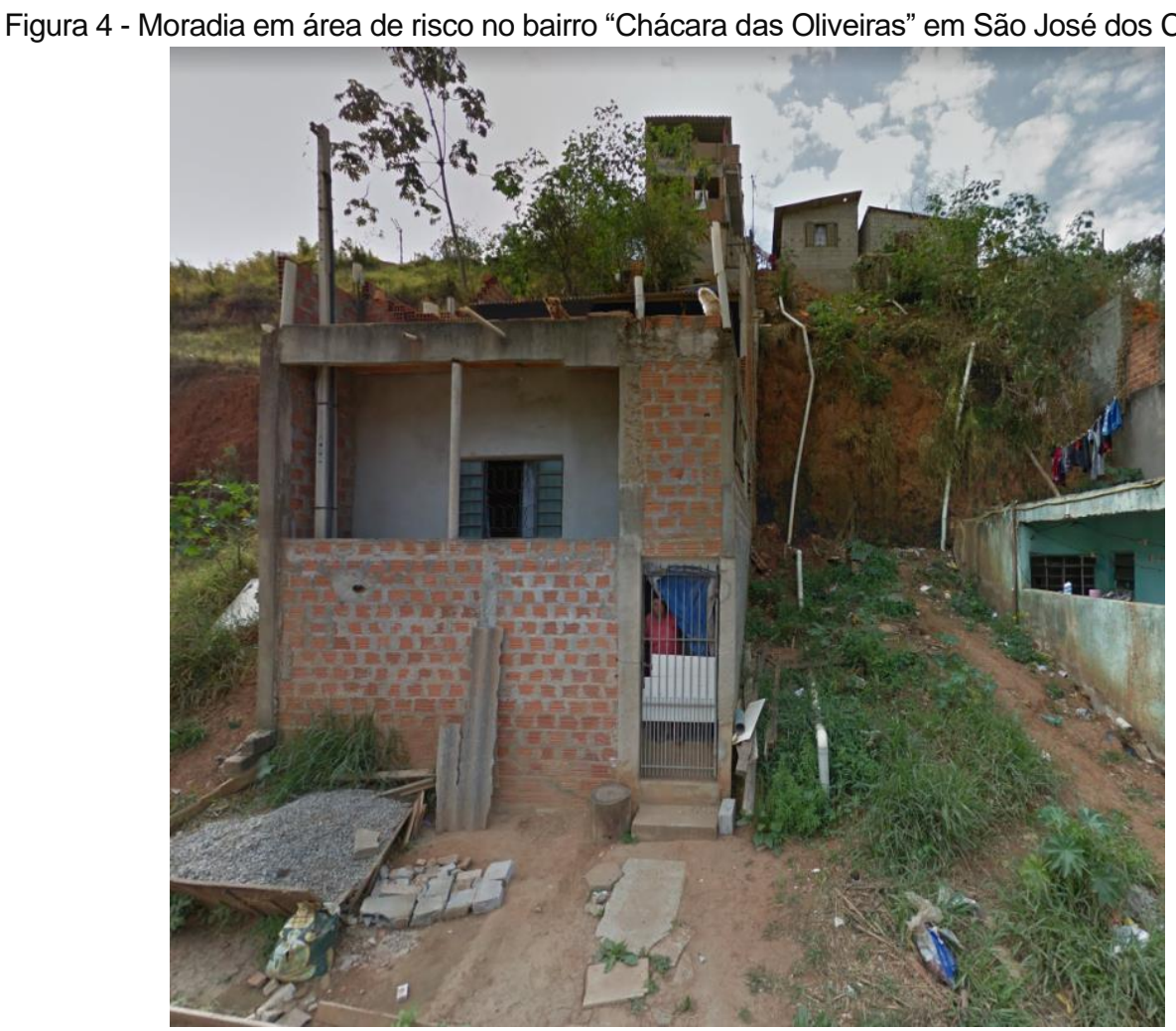

Fonte - Arquivo do autor (2018).

O Plano Diretor de 1961 já apontava o problema de crescimento de loteamentos em zonas rurais (PMSJC,1961, p.07). O Plano Diretor de 1971 também destacou o problema da expansão de loteamentos fora das regras determinadas pelo zoneamento urbano. Esta expansão se intensificou na década de 1980 como consequência do acelerado processo de urbanização e industrialização do município (Gouvêa, 2003). O Plano Diretor de 1995 apontou a existência de 108 loteamentos 
considerados clandestinos e estabeleceu normas que buscavam regularizar esta situação, criando ZEIS (zonas de especial interesse social), que foram destinadas à promoção de habitação de interesse social e à regularização fundiária e urbanística de áreas ocupadas irregularmente. Apenas parte dessas ZEIS foi efetivada (REANI, 2012).

Assim, no PD-1995 com a Carta das Unidades Territoriais e mapeamento dos aspectos físicos do município, foi pensado como seria efetivado o ordenamento, uso e ocupação do solo no município. O PD-1995 proibiu o parcelamento do solo para fins urbanos na zona rural, porém, na prática a lei não foi cumprida e surgiram novos loteamentos considerados clandestinos. Como mostra a Figura 5, houve um aumento na área de loteamentos clandestinos (km2) e em densidade ocupacional ao longo do tempo no município de São José, mesmo com as restrições na legislação.

Figura 5 - Gráfico da distribuição da densidade das ocupações consideradas clandestinas (\%), 2003.

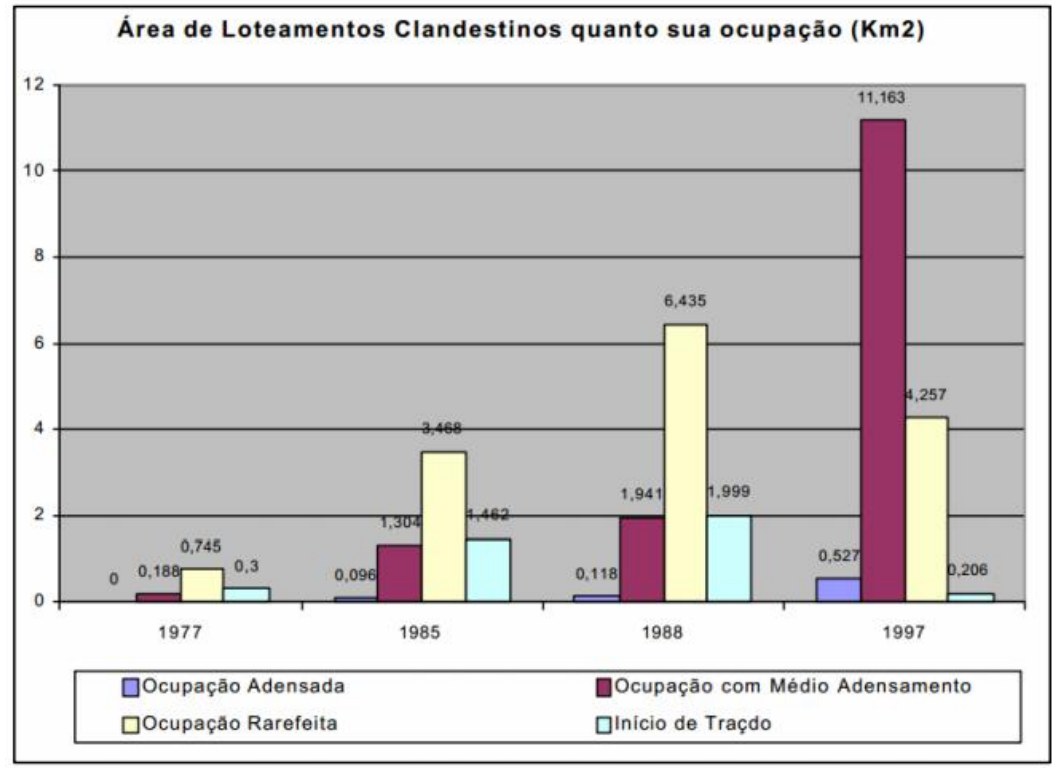

Fonte - Gouvêa (2003, p.101).

Grande parte dos loteamentos considerados clandestinos coincide com áreas de risco mapeadas, áreas de preservação permanente (margens de rios e córregos, áreas com alta declividade e erodibilidade. Em sua maioria estas áreas são ocupadas por pessoas de baixa renda, sem recursos suficientes para construir de acordo com os padrões urbanísticos e de construção civil. Nestas áreas também é precária a oferta de infraestrutura básica, como rede de esgotamento sanitário, abastecimento de água, coleta de lixo. Este fato evidencia que a questão de desastres no município é também um problema social e habitacional. Por parte do poder público, é necessário investir em políticas habitacionais, além de aumentar a fiscalização e controle dos padrões urbanísticos de construção exigidos por lei. $\mathrm{O}$ investimento do poder público em planejamento urbano e em medidas não-estruturais pode promover a redução de risco, e diminuir a oneração dos cofres públicos.

O último Plano Diretor de São José dos Campos, de 2006, se mostra desatualizado, em especial no que se refere a redução de riscos de desastre por não haver um efetivo mapeamento e identificação das áreas de risco, ainda que fossem de conhecimento da Defesa Civil do município, e reconhecendo essa necessidade, em 2016 a Prefeitura avançou neste assunto e organizou estudo visando elaborar o "Plano Municipal para Redução de Risco", onde foram levantadas as áreas de 
risco do município e o número de pessoas expostas ao risco. Neste mesmo ano iniciaram-se os estudos para a revisão do Plano Diretor de 2006, que já completava 10 anos.

No entanto, ainda não houve ações efetivas ou mudanças na legislação municipal, como previsto pelo Estatuto da Cidade e pela Política Nacional de Proteção e Defesa Civil (PNPDEC). Atualmente está em elaboração um novo Plano Diretor. É importante que o novo documento atenda às diretrizes atuais para redução de risco, uma vez que São José possui dezenas de áreas de risco mapeadas com milhares de pessoas expostas ao risco de desastre no município.

\section{CONSIDERAÇÕES FINAIS}

Por meio de análise documental da legislação específica ao planejamento urbano e riscos de desastres, observa-se que a legislação nas esferas federal, estadual e municipal avançou na consideração e na avaliação dos riscos de desastres, incluindo o caso do município de São José dos Campos. A Lei no 12.608/12 (PNPDC) deixa claro que as três esferas devem atuar na redução de risco de desastre, mas o Plano Diretor se mostra como a ferramenta fundamental na esfera local, através do qual o município pode incorporar ações de proteção e defesa civil no planejamento territorial, direcionando o crescimento urbano para as áreas mais favoráveis e impedindo a criação de novas áreas de risco, dessa forma, diminuindo a probabilidade da ocorrência de desastres.

Como determinado no Art.27 da Lei no 12.608/12 (que a altera o Art.12 da Lei no 6.766/79) fica vedada a criação de novos loteamentos e desmembramentos em áreas de risco não edificáveis, que serão definidas no Plano Diretor. A Lei no 12.608/12 determina ainda que o Plano Diretor deverá conter diretrizes para a regularização fundiária de assentamentos urbanos irregulares, e a previsão de áreas para habitação de interesse social por meio da demarcação de zonas especiais de interesse social onde o uso habitacional for permitido (Art.42-A da Lei no 10257/2001, alterado pelo Art.26 da Lei no 12.608/12).

Desta forma, a PNPDEC traz uma série de alterações na Política Urbana, que recaem principalmente sobre o Plano Diretor para o planejamento e desenvolvimento de cidades resilientes aos desastres. A PNPDEC define como competência do município promover a fiscalização das áreas de risco de desastres e vedar novas ocupações nessas áreas (Artigos. 8 e 22). Além destas ações, é imprescindível investir em políticas habitacionais e sociais, uma vez que grande parte das áreas de risco são ocupadas por população carente, que têm nessas áreas a única opção de moradia.

A PNPDEC trouxe grandes contribuições à Política Urbana e ao planejamento urbano, e observouse em São José dos Campos um avanço na legislação e nos Planos Diretores, porém falta coadunação entre as leis e as práticas exercidas pelo poder público municipal, na adoção de medidas estruturais e não estruturais para a redução de desastres. As medidas estruturais como construção de muros de arrimos, relocação de população residente em áreas de risco, construção de reservatórios para evitar inundações, entre outras, são fundamentais na redução de risco, porém causam grande ônus aos cofres públicos. Por outro lado, a adoção de medidas não estruturais como plano de contingência, sensibilização e educação ambiental, fiscalização, planejamento urbano adequado e participação popular, que devem estar presentes no Plano Diretor, podem favorecer a redução de risco de desastres em longo prazo e com menor ônus. Por fim, e mais importante, as comunidades já instaladas em áreas de risco devem receber suporte adequado por parte das três esferas de poder, seja para permanecerem ou para serem realocadas, sempre em diálogo entre as partes.

A Política Nacional de Proteção e Defesa Civil (PNPDEC), associada a políticas habitacionais, urbanísticas e de parcelamento do solo, em especial com o Plano Diretor, tem papel fundamental para o planejamento e crescimento dos munícipios, sendo uma importante ferramenta para redução de risco de desastres em escala local, contribuindo para construção de cidades resilientes, minimizando os danos e prejuízos causados pelos desastres no país.

Caminhos de Geografia Uberlândia-MG v. 21, n. $76 \quad$ Ago/2020

p. 116-133 Página 129




\section{AGRADECIMENTOS}

Este artigo é parte do projeto CNPq 420338/2018-7.

\section{REFERÊNCIAS}

ACSELRAD, H. Vulnerabilidade ambiental, processos e relações. 2006. Comunicação ao II Encontro Nacional de Produtores e Usuários de Informações Sociais, Econômicas e Territoriais, Rio de Janeiro: FIBGE, 2006.

Ambientalização das lutas sociais - o caso do movimento por justiça ambiental. Estudos Avançados, São Paulo, v. 24, n. 68, p. 103-119, 2010, Disponível em: <http://www.scielo.br/scielo.php?script=sci_arttext\&pid=S0103-

40142010000100010\&Ing=en\&nrm=iso>. Acesso em: 28 de ma. de 2019. https://doi.org/10.1590/S0103-40142010000100010

ALMEIDA, P. E. G. A Política Nacional de Proteção e Defesa Civil: os desastres como problema. In: SEMINÁRIO INTERNACIONAL DE CIÊNCIA POLÍTICA, 1., 2015, Porto Alegre. Anais... Porto Alegre, RS: Universidade Federal do Rio Grande do Sul, 2015. Disponível em $<$ https://www.ufrgs.br/sicp/wp-content/uploads/2015/09/ALMEIDA-Paula-Em\%C3\%ADlia-G.-APol\%C3\%ADtica-Nacional-de-Prote\%C3\%A7\%C3\%A3o-e-Defesa-Civil-desastres-como-umproblema-pol\%C3\%ADtico.pdf> Acesso em: 29 de jun. de 2019.

ALVES, H. P. F.; TORRES, H. G. Vulnerabilidade socioambiental na cidade de São Paulo: uma análise de famílias e domicílios em situação de pobreza e risco ambiental. São Paulo em Perspectiva, São Paulo, v. 20, n. 1, p. 44-46, jan./ mar. 2006. Disponível em: $<$ http://www.produtos.seade.gov.br/produtos/spp/v20n01/v20n01 04.pdf $>$ Acesso em: 18 de jun. de 2020.

BRASIL. Ministério de Desenvolvimento Regional. Sistema integrado de informações sobre desastres (S2ID). Disponível em: <https://s2id.mi.gov.br> Acesso em: 10 de out. de 2019.

BRASIL. Constituição (1988). Constituição da República Federativa do Brasil. Brasília, DF: Senado Federal, $1988 . \quad$ Disponível em: <http://www.planalto.gov.br/ccivil_03/constituicao/constituicao.htm> Acesso em: 18 de jun. de 2020.

BRASIL. Lei no 6.766, de 19 de dezembro de 1979. Dispõe sobre o Parcelamento do Solo Urbano e dá outras Providências. Diário Oficial da União, Brasília, DF. Disponível em: $<$ http://www.planalto.gov.br/ccivil_03/leis//6766.htm> Acesso em: 25 de jul. de 2019.

BRASIL. Lei no 10.257, de 10 de julho de 2001. Regulamenta os artigos. 182 e 183 da Constituição Federal, estabelece diretrizes gerais da política urbana e dá outras providências. (Estatuto da Cidade). Brasília: Diário Oficial da União. Disponível em: <http://www.planalto.gov.br/ccivil_03/leis/leis_2001//10257.htm> Acesso em: 25 de jul. de 2019.

BRASIL. Lei no 12.608, de 10 de abril de 2012. Institui a Política Nacional de Proteção e Defesa Civil - PNPDEC; dispõe sobre o Sistema Nacional de Proteção e Defesa Civil - SINPDEC e o Conselho Nacional de Proteção e Defesa Civil - CONPDEC; autoriza a criação de sistema de informações e monitoramento de desastres. Brasília: Diário Oficial da União. Disponível em: $<$ http://www.planalto.gov.br/ccivil_03/_Ato2011-2014/2012/Lei/L12608.htm> Acesso em: 25 de jul. de 2019.

BRASIL. Ministério do Desenvolvimento Regional. Anuário Brasileiro de Desastres Naturais. Brasília: Centro Nacional de Gerenciamento de Riscos e Desastres - CENAD, 2012b. Disponível em: <http://www.mi.gov.br/images/stories/ArquivosDefesaCivil/ArquivosPDF/publicacoes/Anuariode-Desastres-Naturais-2011.pdf> Acesso em: 01 de jul. de 2019.

CARLOS, A. F. A. A (re)produção do espaço urbano. São Paulo: Edusp, 2008. 272 p.

O espaço urbano: novos escritos sobre a cidade. São Paulo: Labur Edições, 2007. $184 \mathrm{p}$. 
CARVALHO, C. S.; GALVÃO, T. Gestão de riscos e resposta a desastres naturais: a atuação do Ministério das Cidades. In: CONGRESSO CONSAD DE GESTÃO PÚBLICA, 6, 16, 17 e 18 abr. 2013, Brasília. Anais... Brasília, DF: Centro de Convenções Ulysses Guimarães, 2013. Disponível em: <http://consadnacional.org.br/wp-content/uploads/2013/05/071-GEST\%C3\%83O-DE-RISCOSE-RESPOSTA-A-DESASTRES-NATURAIS-A-ATUA\%C3\%87\%C3\%830-DOMINIST\%C3\%89RIO-DAS-CIDADES.pdf> Acesso em: 01 de jul. de 2019.

FERREIRA, D.; ALBINO, L.; FREITAS, M. J. C. C. Participação popular na prevenção e enfrentamento de desastres ambientais: resultado de um estudo piloto em Santa Catarina, Brasil. Revista Geográfica de América Central, Costa Rica, v. 2. n. 47E, p. 1-17, 2011. Disponível em: $<$ https://www.revistas.una.ac.cr/index.php/geografica/article/view/2530> Acesso em: 18 de jun. de 2020.

GOUVÊA, R. A. R. O espaço urbano e a clandestinidade: um estudo de caso dos loteamentos clandestinos no município de São José dos Campos-SP. 2003. 234 f. Dissertação (Mestrado em Planejamento Urbano e Regional) - Instituto de Pesquisa e Desenvolvimento - IPD, Universidade do Vale do Paraíba, São José dos Campos, 2003.

IBGE - Instituto Brasileiro de Geografia e Estatística. Perfil das cidades brasileiras: população estimada no município de São José dos Campos em 2019. Disponível em: <https://cidades.ibge.gov.br/brasil/sp/sao-jose-dos-campos/panorama> . Acesso em: 18 jun. 2020.

Censo Demográfico 2010. Disponível em: <https://cidades.ibge.gov.br/brasil/sp/sao-josedos-campos/panorama> Acesso em: 01 de set. de 2019.

LEFEBVRE, H. La production de l'espace. L'homme et la société, n. 31-32, p. 15-32, 1974.. Disponível em: <https://www.persee.fr/doc/homso 0018-4306 1974 num 311 1855> Acesso em: 18 de jun. de 2020. https://doi.org/10.3406/homso.1974.1855

MARTINS, M. L. R. São Paulo: além do Plano Diretor. Estudos Avançados, São Paulo, v. 17. n. 47, p. 167-186, 2003. Disponível em: <https://www.scielo.br/pdf/ea/v17n47/a10v1747.pdf> Acesso em: 18 de jun. de 2020. https://doi.org/10.1590/S0103-40142003000100010

MENDES, R. M.; VALÉRIO FILHO, M.; BERTOLDO, M. A.; DA SILVA, M. F. Estudo de limiares críticos de chuva deflagradores de deslizamentos no município de São José dos Campos/SP. Territorium, Coimbra, n. 22, p. 119-129, 2015. Disponível em: <https://impactumjournals.uc.pt/territorium/article/view/1647-7723 22 8/2446> Acesso em: 18 jun. 2020. https://doi.org/10.14195/1647-7723 228

PMSJC - Prefeitura Municipal de São José dos Campos. Plano Preliminar do Plano Diretor de Desenvolvimento Integrado de 1961. CPEU,FAU,USP. Arquivo da Secretaria de Planejamento Urbano de São José dos Campos. Paço Municipal. São José dos Campos, 1961.

Lei Municipal .no 1.606, de 13 de setembro de 1971. Estabelece as zonas em que ficam divididas o município de são josé dos campos, para efeito de uso do solo e edificações, e dá outras providências. Disponível em: <https://leismunicipais.com.br/a/sp/s/sao-jose-dos-campos/leiordinaria/1971/160/1606/lei-ordinaria-n-1606-1971-estabelece-as-zonas-em-que-ficam-divididas-omunicipio-de-sao-jose-dos-campos-para-efeito-de-uso-do-solo-e-edificacoes-e-da-outrasprovidencias>. Acesso em: 01 jan. 2019.

Lei Municipal no 1.623, de 30 de novembro de 1971. Institui o Plano Diretor de Desenvolvimento Integrado do Município de São José dos Campos, e dá outras providências. Disponível em: <http://www.ceaam.net/sjc/legislacao/> Acesso em: 1 set. 2019.

.Caderno Técnico do Plano Diretor de 1995. (a) Disponível em: <http://www.sjc.sp.gov.br/secretarias/planejamento urbano.aspx>. Acesso em: 01 de set. de 2019.

.Lei Complementar n. 121, de 27 de abril de 1995. (b) Dispõe sobre a Política Territorial e Urbana do Município, institui o Plano Diretor de Desenvolvimento Integrado da Cidade de São José dos Campos, e dá outras providências. Disponível em: <http://www.ceaam.net/sic/legislacao/>. Acesso em: 01 de set. de 2019. 
.Caderno Diagnóstico do Plano Diretor de 2006. Disponível em: $<$ http://www.sjc.sp.gov.br/secretarias/planejamento urbano.aspx>. Acesso em: 01 de set. de 2019.

Lei Complementar no 306, de 17 de novembro de 2006. Aprova e institui o Plano Diretor de Desenvolvimento Integrado - PDDI do Município de São José dos Campos para o próximo decênio e dá outras providências. Disponível em: <http://www.ceaam.net/sjc/legislacao $>$. Acesso em: 01 de set. de 2019.

Caderno Diagnóstico da Lei de Zoneamento de 2010. Disponível em: <http://www.sjc.sp.gov.br/secretarias/planejametno urbano.aspx>. Acesso em: 01 de set. de 2019.

Avaliação de Áreas de Risco do Município de São José dos Campos. Produto II: Relatório Preliminar do Plano Municipal de Redução de Risco (PMRR). Fase I. 2016. Disponível em: <http://www.sjc.sp.gov.br/media/703432/pmr__relatorio_preliminar.pdf> Acesso em: 01 de set. de 2018.

QUATRO pessoas morrem após deslizamento de terra em São José. Terra deslizou sobre casa na noite deste sábado (5) na zona norte. Uma mulher, dois adolescentes e uma criança foram encontrados sem vida. Portal G1, Vale do Paraíba. 6 mar. 2016. Disponível em: <http://g1.globo.com/sp/vale-do-paraiba-regiao/noticia/2016/03/quatro-pessoas-morrem-aposdeslizamento-de-terra-em-sao-jose.html> Acesso em: 01 de abr. de 2019.

REANI, R. T. Organização do espaço e políticas públicas ambientais no município de São José dos Campos - SP. 2012. 300 f. Tese (Doutorado em Geografia Humana ) - Faculdade de Filosofia, Letras e Ciências Humanas, Universidade de São Paulo, São Paulo, 2012.

ROBAINA, L. E. S. Espaço urbano: relação com os acidentes e desastres naturais no Brasil. Ciência e Natura, Santa Maria, v. 30, n. 2, p. 93-105, 2008. Disponível em: $<$ https://periodicos.ufsm.br/cienciaenatura/article/viewFile/9841/5900> Acesso em: 18 de jun. de 2020.

ROBAINA, L. E. S.; KORMANN, T. C.; WIGGERS, M. M.; SCCOTI, A. A. V. Análise espaçotemporal das ocorrências de inundações e movimentos de massa no município de Caxias do Sul, RS. Ciência e Natura, Sana Maria, v. 32, n. 1, p. 159-172, 2010. Disponível em: $<$ https://periodicos.ufsm.br/cienciaenatura/article/view/9504/5653> Acesso em: 18 de jun. de 2020.

SANTOS, L. B. L. et al;. Desastres naturais de origem hidrológica e impactos no setor de transportes - o caso de março de 2015 em São José dos Campos-SP. In Simpósio Brasileiro de Recursos Hídricos, XXI, 2015, Brasília. Anais... Brasília, DF: ABRH, 2015. Disponível em: $<$ http://eventos.abrh.org.br/xxisbrh/index.php> Acesso em: 18 de jun. de 2019.

SANTOS, A. R. Enchentes e deslizamentos: causas e soluções. São Paulo: Pini, 2012. 128 p.

SÃO PAULO. Lei Complementar no 1.166 de 09 de janeiro de 2012. Cria a região metropolitana do Vale do Paraíba e Litoral Norte, e dá providências correlatas. Assembleia Legislativa do Estado de São Paulo, São Paulo, SP, 10 jan. 2012. Disponível em: $<$ https://www.al.sp.gov.br/repositorio/legislacao/lei.complementar/2012/lei.complementar-116609.01.2012.html> Acesso em: 18 de jun. de 2020.

SEABRA, O. C. L. A Geografia Urbana que fazemos. Revista do Departamento de Geografia, São Paulo, volume especial 30 anos, p. 284-307, dez. 2012 Disponível em: $<$ http://www.revistas.usp.br/rdg/article/view/53852> Acesso em: 18 de jun. de 2020. https://doi.org/10.7154/RDG.2012.0112.0014

SEADE - Fundação Sistema Estadual. Portal de Estatísticas do Estado de São Paulo. Perfil dos municípios paulistas: informações sobre território e população da Região Metropolitana do Vale do Paraíba e Litoral Norte em 2020. Disponível em: <https://perfil.seade.gov.br/> Acesso em: 18 de jun. de 2020.

TUCCI, C. E. M. Gestão de inundações urbanas. Porto Alegre: Ministério das Cidades, Global WaterPartnership, World Bank, Unesco, 2005. 
Regina Tortorella Reani

Érico Soriano

Luciana R Londe

Interfaces legais entre planejamento urbano

Lívia Rodrigues Tomás

UNISDR - Escritório das Nações Unidas para a Redução do Risco de Desastres. Terminology for

Disasters. 2017.2 Disponível em: <https://www.preventionweb.net/files/50683_oiewgreportenglish.pdf>Acesso em: 01 de abr. de 2019.

VALENCIO, N. F. L da S. Dimensões psicossociais e político-institucionais do desastre de Camará (PB) limitações da resposta da Defesa Civil frente ao rompimento de barragens. In:ENCONTRO DE CIÊNCIAS SOCIAIS E BARRAGENS, I, 2005, Rio de Janeiro. Anais... Rio de Janeiro, RJ: IPPUR/UFRJ, 2005.

VEDOVELlO, R.; MACEDO, E. S. Deslizamento de encostas. In SANTOS, R. F. (Org.). Vulnerabilidade ambiental: desastres naturais ou fenômenos induzidos? Brasília: Ministério do Meio Ambiente, 2007. p. 75-93. Disponível em: <https://fld.com.br/wpcontent/uploads/2019/07/Vulnerabilidade Ambiental Desastres Naturais ou Fenomenos Induzido s.pdf> Acesso em: 18 de mai. de 2020.

Recebido em: 04/12/2019

Aceito para publicação em: 29/06/2020 